\title{
Laser-Induced Forward Transfer Direct-Write of Miniature Sensor and Microbattery Systems
}

\author{
A. Piqué, C.B. Arnold, R.C. Wartena, D.W. Weir, B. Pratap, K.E. Swider-Lyons, R.A. \\ Kant, and D.B. Chrisey \\ Naval Research Laboratory, Code 6372, 4555 Overlook Ave., S.W. \\ Washington, DC 20375, USA \\ E-mail:pique@nrl.navy.mil
}

\begin{abstract}
Direct-Write techniques have the potential to revolutionize the way miniature sensor devices and microbattery systems are designed and fabricated. The Naval Research Laboratory has developed an advanced laser-based forward transfer process for direct writing novel structures and devices comprising of metals, ceramics, polymers and composites under ambient conditions on both ceramic and plastic substrates. Using this forward transfer technique, we have demonstrated the ability to rapidly prototype various types of physical and chemical sensor devices, and microbatteries. The laser forward transfer process is computer controlled which allows the design of the devices to be easily modified and adapted to any specific application. Furthermore, the same process enables the fabrication of complete sensor or power-source systems by incorporating the passive electronic components required for sensor readout or power management. Examples are provided of various types of miniature sensors, and prototype alkaline and $\mathrm{Li}$-ion microbatteries fabricated using this technique.
\end{abstract}

Keywords: Laser transfer, MAPLE Direct-Write, Direct-Write of sensors, Direct-Write of microbatteries

\section{Introduction}

Current trends for developing advanced electronic and sensor systems place emphasis in achieving performance levels generally associated with integrated circuits. This requires further miniaturization, while enhancing the functionality and reliability of existing components. It also requires new strategies to eliminate the long lead times required for the fabrication of prototypes and evaluation of new materials and designs. In particular, for sensor and micro-power sources development, the trend is toward the fabrication of micron-scale devices which can be incorporated into any type of platform. ${ }^{1)}$

Direct-write techniques, which do not require photolithographic processing steps, provide an alternative for the development and fabrication of the above described systems. Direct-write technologies do not compete with photolithography for size and scale, but rather complement it in specific applications requiring rapid turnaround and/or pattern iteration, conformal patterning, or for modeling difficult circuits. ${ }^{1)}$ Examples of direct-write technologies for fabricating or modifying metallic interconnects and/or other electronic passive elements include ink jet printing, ${ }^{2)}$ direct-write of ceramic slurries (Micropen $\odot$ ), ${ }^{3)}$ laser trimming $^{4)}$ and laser chemical vapor deposition (LCVD). However, none of the above techniques is capable of operating in air and at room temperature while maintaining sub-10- $\mu \mathrm{m}$ resolution and without requiring ex situ processing. Furthermore, more than one technique must be used to deposit and process the range of materials employed for the fabrication electronic, sensor and power generation devices.

Over the past decade, various laser-based direct-write techniques have been developed for depositing different types of materials such as metals for interconnects and mask repair. More recently, a new laser-based direct-write technique, called MAPLE DW, for Matrix-Assisted Pulsed-Laser Evaporation Direct-Write, has been used for the direct-write of conformal electronic devices, ${ }^{6-9)}$ phosphor materials ${ }^{10)}$ microbatteries ${ }^{11,12)}$ and even viable biomaterials. ${ }^{13,14)}$ In this paper, we describe the use of the MAPLE DW technique for the fabrication of temperature, strain and chemical sensors as well as prototype alkaline and Li-ion microbatteries.

\section{Background}

MAPLE DW, is a laser-based processing technique that was originally developed to fabricate and rapidly prototype mesoscopic electronic devices utilizing matrices containing metallic, dielectric or resistive materials. ${ }^{5)}$ This approach, however, is gentle enough to successfully form patterns and three-dimensional structures of a wide variety 
of organics, including chemically sensitive polymers, active proteins and antibodies as well as viable cells. ${ }^{13,14)}$

MAPLE DW involves the forward transfer of materials from a UV-transparent support to a receiving substrate. The transfers are performed by mixing the active, or sensitive material in a UV-absorbent matrix to form an "ink". The ink is then applied to the UV-transparent support to form the "ribbon" as shown in Figure 1. A focused UV laser pulse is directed through the backside of the ribbon so that the laser energy interacts with the matrix at the support interface. The UV microscope objective that focuses the laser at the interface also serves as an optical guide to determine the region of the ribbon to be transferred. Layers of matrix near the support interface evaporate due to localized heating from the laser-material interaction. This vaporization releases the remaining ink by gently and uniformly propelling it away from the support. In this manner, MAPLE DW is capable of producing passive electronic devices (i.e., interconnects, resistors, capacitors) with line widths of the order of 10 $\mu \mathrm{m}$. By removing the ribbon and allowing the laser pulse to interact with the substrate, this approach is also able to micromachine channels and through vias into polymer, semiconductor, and metal surfaces as well as trim deposited structures to meet design specifications. All micromachining and material transfer can be controlled by computer (CAD/CAM), which enables this tool to rapidly fabricate complex structures without the aid of masks or moulds. This technique, therefore, has the potential to fabricate by a single tool, complete prototype systems on a single substrate including the sensor coating, transducer, support electronics and even the microbatteries required to power the whole assembly.

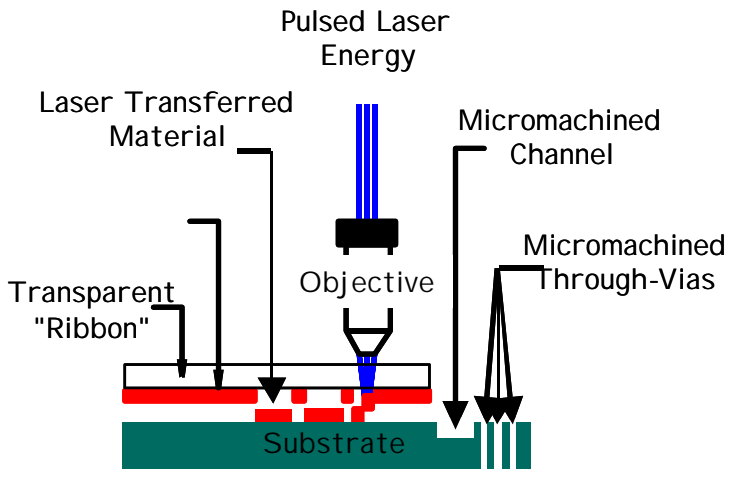

Figure 1. Schematic diagram of the MAPLE DW process.

\section{Experimental}

\subsection{MAPLE DW Ribbon Preparation}

Borosilicate glass discs, double side polished, $5.0 \mathrm{~cm}$ diameter $\mathrm{x} 3 \mathrm{~mm}$ thick were used as ribbon supports. For the fabrication of the temperature and strain sensors, a screen printable silver paste (Parmod RRA-100, from Paralec, Inc.) was applied to one side of the discs using a
\#4 wire-coater (Gardner, Inc.) to form an ink layer about 5 $10 \mu \mathrm{m}$ thick. For the fabrication of the cathodes for the alkaline microbatteries, powders of $\mathrm{MnO}_{2} \quad(<425$ mesh, JEC) and $\mathrm{Ag}_{2} \mathrm{O}$ ( $<325$ mesh, Alfa) were each mixed with 5 to $20 \mathrm{wt} \%$ of acetylene carbon black (Alfa). The resulting powders were mixed with a solution comprised of equal parts of $0.1 \mathrm{~N} \mathrm{KOH}$ and glycerol (Alfa) by weight until forming a uniform paste to make the $\mathrm{MnO}_{2}$ and $\mathrm{Ag}_{2} \mathrm{O}$ inks respectively. For the fabrication of the anodes, $\mathrm{Zn}$ powders (3 $\mu \mathrm{m}$ dia., GoodFellow), were mixed with a solution of equal parts by weight of $9 \mathrm{~N} \mathrm{KOH}$ and glycerol until forming a uniform paste. These pastes were then applied to one side of the borosilicate glass discs using a \#4 wire-coater to form a $510 \mu \mathrm{m}$ thick ink layer. Inks for the Li-ion electrodes were comprised of lithium cobalt oxide, KS6 carbon and an organic binder (polyvinylidene fluoride or PVDF) for the cathode and MCMB 2528 carbon with PVDF for the anode. Both electrodes were made into a slurry by adding 1methyl-2-pyrrolidinone as a solvent and cast onto the ribbon as described above. In the case of the chemical sensors, the ribbons were prepared by spray coating a solution containing $0.1 \mathrm{gm}$ of polyepichlorohydrin $(\mathrm{PECH}$, average $\mathrm{MW}=700000$, Aldrich) and $0.01 \mathrm{gm}$ of acetylene carbon black (Alfa) mixed in $50 \mathrm{ml}$ of chloroform.

The coated side of the ribbons was kept at a distance of 100-200 $\mu \mathrm{m}$ from the substrate with a spacer. Both the substrate and the ribbon were held in place using a vacuum chuck over the X-Y substrate translation stage. The third harmonic emission of a Nd:YAG laser, $\lambda=355 \mathrm{~nm}$ (Spectra Physics), was directed through a circular aperture and a 10x objective lens, resulting in a $85 \mathrm{~mm}$ diameter spot at the ribbon. The laser fluence varied between $0.1-$ $1.0 \mathrm{~J} / \mathrm{cm}^{2}$ depending on the material being transferred, and was estimated by averaging the total energy of the incident beam over the irradiated area.

\subsection{Temperature and Strain Sensor Fabrication and Testing}

Silver conductive lines were transferred from the silver paste ribbons by MAPLE DW onto polyimide substrates and used as temperature and strain sensors. The length and layout of the lines was easily modified via computer control in order to achieve $\sim 10-\mu \mathrm{m}$ thick and $\sim 100-\mu \mathrm{m}$ wide patterns. The silver ink was dried at $100{ }^{\circ} \mathrm{C}$ on a hot plate to remove excess solvent and then cured at $280{ }^{\circ} \mathrm{C}$ in an oven for $10 \mathrm{~min}$ to decompose the organic silver precursors in order to form conductive patterns. Patterns in the form of serpentine lines were evaluated as temperature sensors by comparing their change in resistance to the response of a type $\mathrm{K}$ thermocouple. One of the MAPLE DW serpentine patterns and a thermocouple were mounted next to each other and exposed to heat pulses generated by a heat gun over a temperature range of 24 to $60{ }^{\circ} \mathrm{C}$. A second pattern was evaluated as a strain sensor by measuring its resistance change as a function of deflection 
due to an applied force. The resistance of the serpentine was measured using a computer controlled 34401A digital multimeter (Agilent).

\subsection{Chemical Sensor Fabrication and Testing}

For the chemical sensors, $1 \mathrm{~mm} \times 4 \mathrm{~mm}$ pads of $\mathrm{PECH} /$ carbon were deposited by MAPLE DW over silver interdigitated electrodes. To verify the operation of the MAPLE DW sensors, similar pads of $\mathrm{PECH} /$ carbon were spray coated onto a second set of silver electrodes. The silver electrodes were deposited by MAPLE DW onto polyimide substrates in the same way as the serpentine lines. The response of the $\mathrm{PECH} /$ carbon sensors was evaluated by challenging them with controlled exposures of toluene and dimethylmethylphosphonate (DMMP) vapor streams. The carrier air temperature and humidity were controlled with a Miller Nelson HCS-301 airhumidity generator. An automated Harvard 22 liquid syringe pump system was utilized to generate analyte vapor by injecting the liquid analyte into a heated evaporation plate system. The resulting vapor was mixed with humidified carrier air and passed into a test chamber housing the chemical sensors. The test chamber consisted of a hermetic enclosure with opposite inlet and outlet gas ports, to allow vapor flow over the sensors.

\subsection{Microbattery Fabrication and Testing}

Separate $\mathrm{MnO}_{2}$ and $\mathrm{Ag}_{2} \mathrm{O}$ pads $2 \mathrm{~mm}$ x $3 \mathrm{~mm}$ in area and $40 \mu \mathrm{m}$ thick were laser transferred onto $1 \mathrm{~cm}^{2}$ gold-coated glass substrates. The pads were heated to $150{ }^{\circ} \mathrm{C}$ in an oven for $30 \mathrm{~min} \mathrm{~b}$ remove the glycerol. Then a $4 \mathrm{~mm} \times 5$ $\mathrm{mm} \times 2 \mu \mathrm{m}$ thick film formed by drop casting separate layers of ethyl cellulose (Aldrich) and Nafion ${ }^{\circledR}$ was prepared over each of the $\mathrm{MnO}_{2}$ and $\mathrm{Ag}_{2} \mathrm{O}$ pads to serve as the separator between the metal oxide cathode and the $\mathrm{Zn}$ anode. A $\mathrm{Zn}$ layer was then laser transferred onto the ethyl cellulose in the form of a $2 \mathrm{~mm} \times 25 \mathrm{~mm}$ x $20 \mu \mathrm{m}$ pad. At this point, the resulting $\mathrm{MnO}_{2} /$ separator/Zn and $\mathrm{Ag}_{2} \mathrm{O} /$ separator/Zn structures were ready for evaluation.

The lithium-ion electrodes were fabricated onto separate substrates as pads $3 \mathrm{~mm} \times 3 \mathrm{~mm} \times 40 \mu \mathrm{m}$ thick. Lithium cobalt oxide was transferred onto aluminum substrates while the carbon electrode was transferred onto a copper substrate. After transfer, the electrodes were dried in a vacuum oven for 12 hours at $110{ }^{\circ} \mathrm{C}$. The electrodes were then submerged in a $1 \mathrm{M} \mathrm{LiClO}_{4} /$ propylene carbonate electrolyte solution for 12 hours prior to their electrochemical evaluation. Half-cell measurements for determining the charging and discharging characteristics were performed at a 12-hour rate in free electrolyte versus a $\mathrm{Li} / \mathrm{Li}^{+}$reference electrode and lithium counter electrode.

Chronopotentiometry of the zinc/ $\mathrm{MnO}_{2}$ alkaline microbatteries and lithium-ion electrodes was performed using an EG\&G PAR 263 potentiostat driven with M270 software. The thickness of both the ink ribbons and the dried pads were determined via sylus profilometry (Tencor P10).

\section{Results and Discussion}

\subsection{Temperature and Strain Sensors}

Using MAPLE DW, we have demonstrated a simple temperature sensor on a polyimide substrate. A silver serpentine line about $10 \mathrm{~cm}$ long, occupying a $5 \mathrm{~mm} \mathrm{x} 5$ $\mathrm{mm}$ area and with a resistance of about $93 \mathrm{ohms}$ was made by MAPLE DW as shown in Figure 2(a). The response of the MAPLE DW temperature sensor to a heat pulse from a heat gun mirrored that of an adjacent thermocouple and it is shown in Figure 2(b). The variation in resistance as a function of temperature was calibrated against a type $\mathrm{K}$ thermocouple resulting on a $\Delta \mathrm{R} / \Delta \mathrm{T}$ of $0.21 \mathrm{ohms} / \mathrm{K}$ for the sensor element. The same device was then mounted on a cantilever and its resistance was monitored as a function of the deflection caused by various weights. The response of this simple strain sensor is shown on Figure 2(c). A linear fit of the data reveals a $5.2 \mathrm{ohm} / \mathrm{N}$ resistance over applied force response.

\subsection{Chemiresistor Gas Sensor}

By using dispersions of conductive materials such as carbon and non-conductive chemoselective polymers, gas sensors based on conductimetric techniques ${ }^{15,16)}$ can be fabricated. In the correct ratio, the polymer/carbon composite becomes conductive and its resistance will change when exposed to different vapors, as shown
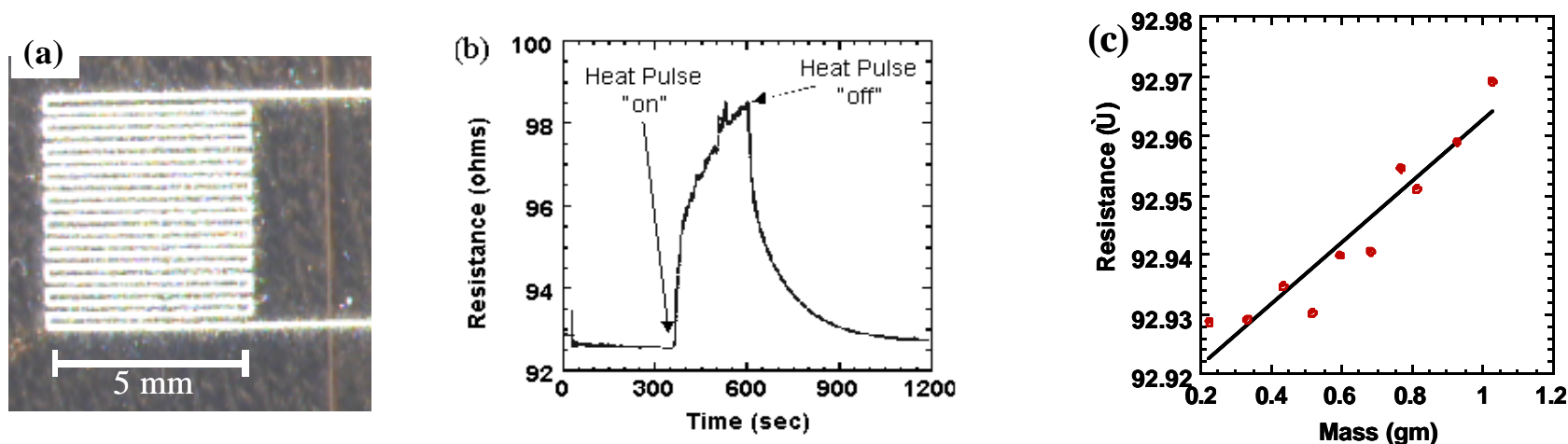

Figure 2. (a) Photograph of a temperature sensor made by MAPLE DW of a silver serpentine line on a polyimide substrate. (b) Response of this sensor to a heat pulse. (c) Response of the sensor as a function of deflection caused by various weights (the straight line shows a linear fit to the data). 
schematically in Figure 3(a). These types of chemical sensors are known as chemiresistors and are extremely simple to operate and ideally suited for miniaturization and manufacture in array form. For this work, PECH was selected since it is a polymer with a range of solubilities to numerous analytes, making it well suited for the fabrication of chemical gas sensors with broad applicability to a variety of different types of analytes.

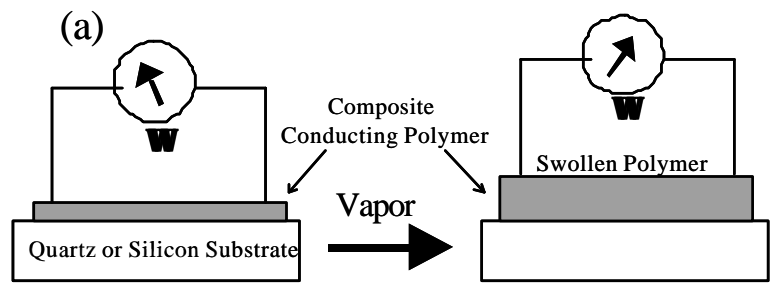

(b)

\section{Ag Interdigitated} Electrodes

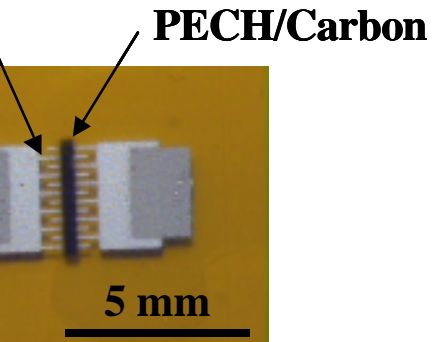

Figure 3. (a) Schematic showing the basic operation of a chemiresistor sensor. (b) Optical micrograph of a chemiresistor gas sensor element fabricated entirely by MAPLE DW.

Figure 3(b) shows a micrograph of a typical PECH/carbon chemiresistive pad fabricated by MAPLE DW across a set of silver interdigitated electrodes also made by MAPLE DW on a polyimide substrate. To evaluate the performance of the chemiresistors made by MAPLE DW, similar $\mathrm{PECH} /$ carbon pads were fabricated by spray coating and placed side-by-side and exposed to calibrated concentrations of analyte vapors. Toluene and DMMP were used as analytes. Toluene and DMMP cover a range of solubility properties from a low polarity hydrocarbon to a polar and hydrogen-bond basic phosphonate ester. Toluene is a chemical present in diesel vapor, while DMMP is a simulant and precursor for chemical nerve agents. The results of the vapors tests indicated that the response of the MAPLE DW and that of the spray coated chemiresistors were similar and showed sensitivities of the order of parts per million (ppm). The response of both chemiresisitors when exposed to various concentrations of toluene and DMMP vapors are shown in Figure 4.

The real potential of MAPLE DW is made clear when a complete sensor system consisting of a single sensor element, interconnects and passive electronic components is fabricated using this laser direct-write technique. An actual working example is provided in Figure 5 which shows a photograph of a complete self contained chemical sensor system manufactured on a $5 \mathrm{~cm}$ x $5 \mathrm{~cm}$ polyimide substrate. The majority of the components shown on this image, including the chemiresistor, the $\mathrm{Ag}$ interconnects and the polymer thick film resistors, but not the LED's and the 4-quad comparator IC (which were soldered to the circuit afterwards), were fabricated by MAPLE DW. Future plans include the fabrication of multiple sensor elements in the form of arrays and the addition of microbatteries all made by MAPLE DW.

\subsection{Alkaline Microbatteries}

An schematic showing the cross-section of the MAPLE DW stacked alkaline microbattery is shown in Figure 6(a). Figure 6(b) shows a top view micrograph of a $\mathrm{zinc} / \mathrm{MnO}_{2}$ alkaline microbattery made this way on top of a gold-
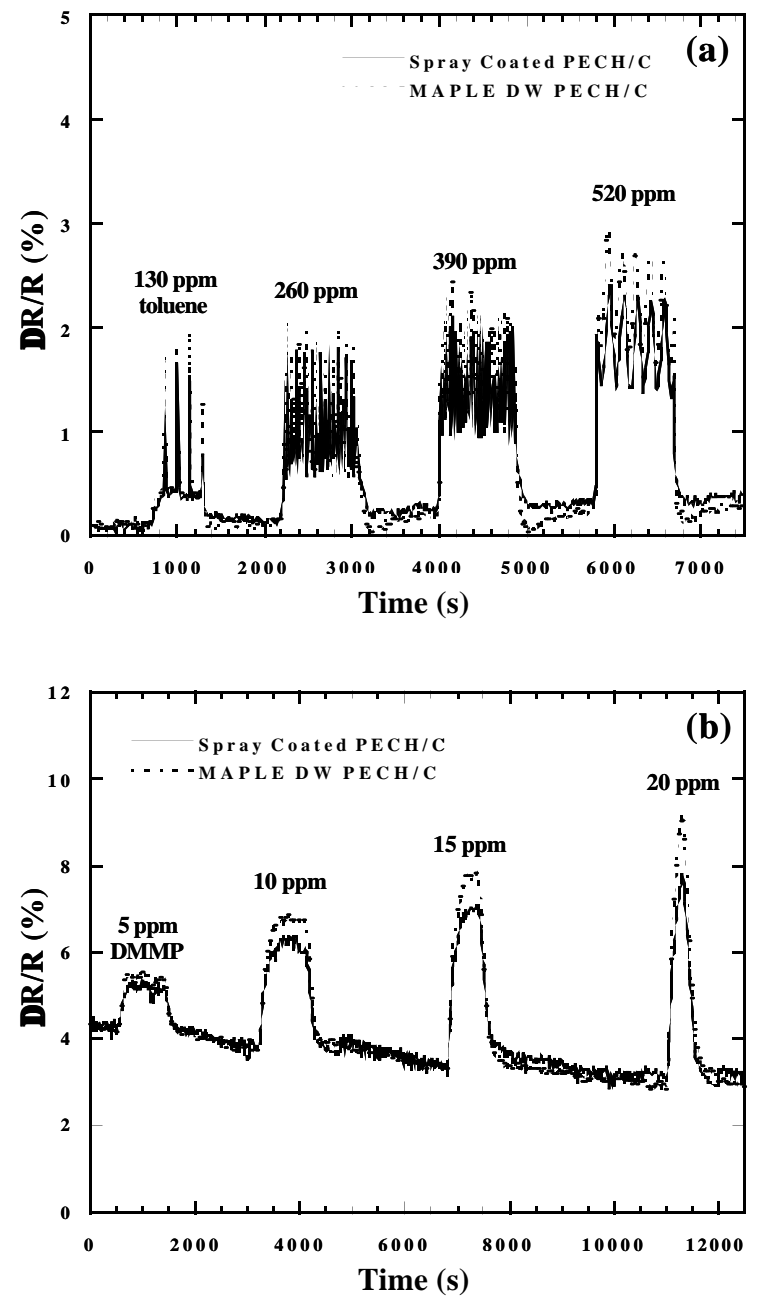

Figure 4. Response of a spray coated and a MAPLE DW $\mathrm{PECH} /$ carbon chemiresistor sensors to various concentrations of (a) toluene and (b) DMMP vapors. The spikes on the toluene response signals are due to the syringe pump system used to generate the calibrated vapor exposures. 
coated glass substrate. We have also successfully fabricated stacked alkaline microbatteries in which the top $\mathrm{Zn}$ layer overlays the electrolyte and is in contact with the

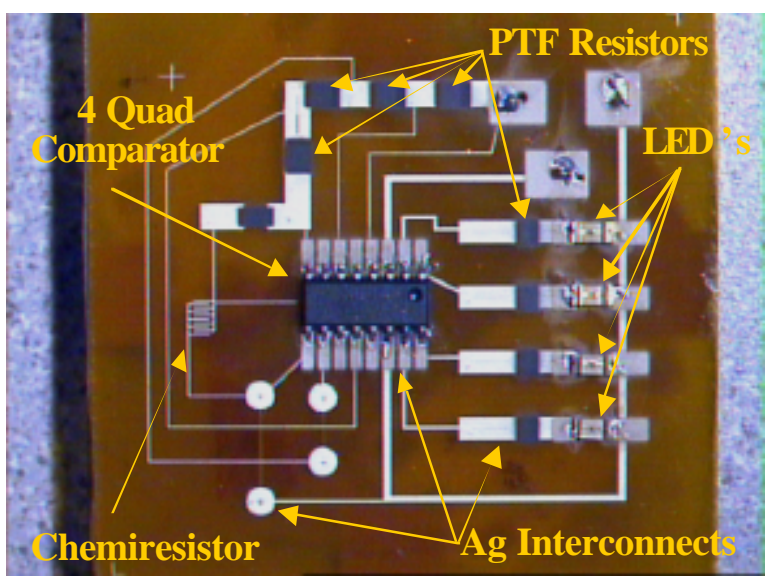

\section{$2.5 \mathrm{~cm}$}

Figure 5. Photograph of a working chemiresistor sensor system made by MAPLE DW. The photograph shows all the elements of the sensor except for the batteries which are mounted on the back.

bottom electrode. ${ }^{12)}$ After the zinc pad is laser deposited, a small carbon paper current collector is placed on top of the zinc and the microbatteries are ready to be tested. The zinc/ $\mathrm{MnO}_{2}$ alkaline microbatteries have the expected cell voltage of $1.5 \mathrm{~V}$, while the $\mathrm{zinc} / \mathrm{Ag}_{2} \mathrm{O}$ microbatteries showed the expected voltage of $1.6-1.8 \mathrm{~V}$.

(a)

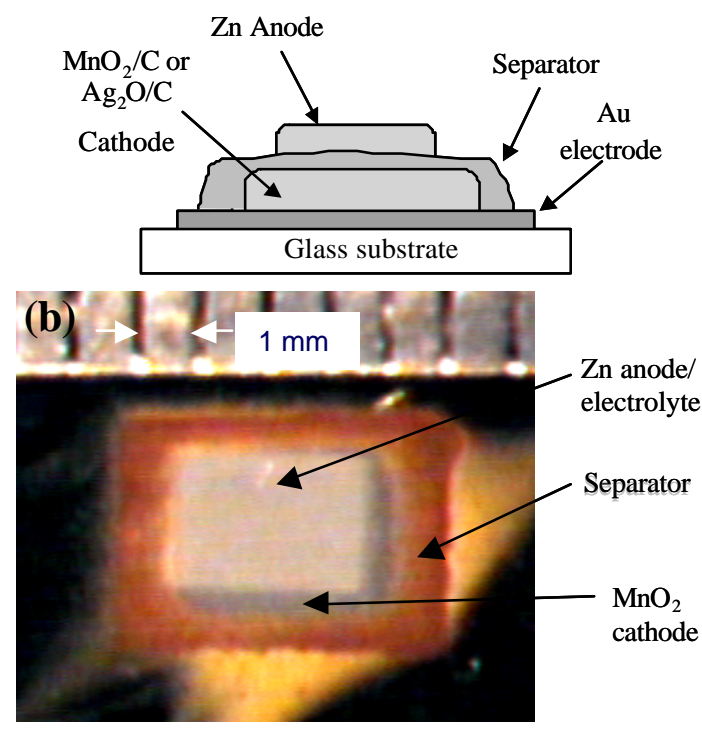

Figure 6. (a) Cross section schematic of the stacked alkaline microbatteries made by MAPLE DW. (b) Optical micrograph of a $\mathrm{Zn} / \mathrm{MnO}_{2}$ microbattery.

It should be pointed out that none of the alkaline microbatteries fabricated for this work were packaged and thus the $\mathrm{KOH}$ electrolyte solution would evaporate with time. Figure 7 shows the discharge and charge characteristics of a zinc/ $\mathrm{MnO}_{2}$ alkaline microbattery. The specific energy of these batteries is approximately ten times lower than expected, due to the high resistance of the ethyl cellulose/Nafion ${ }^{\circledR}$ separator. Despite this, one of the zinc/ $\mathrm{MnO}_{2}$ alkaline microbatteries was connected to a digital watch and was able to power it for over 10 minutes as shown in Figure 8.

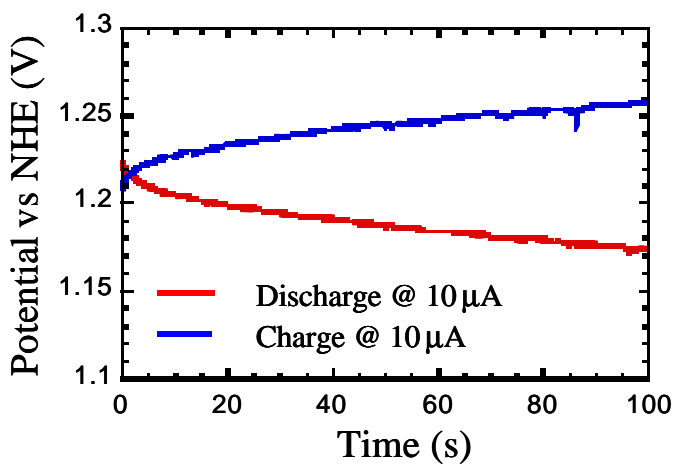

Figure 7. Charge Discharge behavior of a $\mathrm{Zn} / \mathrm{MnO}_{2}$ microbattery made by MAPLE DW.

Future work will focus in increasing the specific energy of these alkaline microbatteries by using other materials as separator layers, and in developing and testing various packaging schemes.

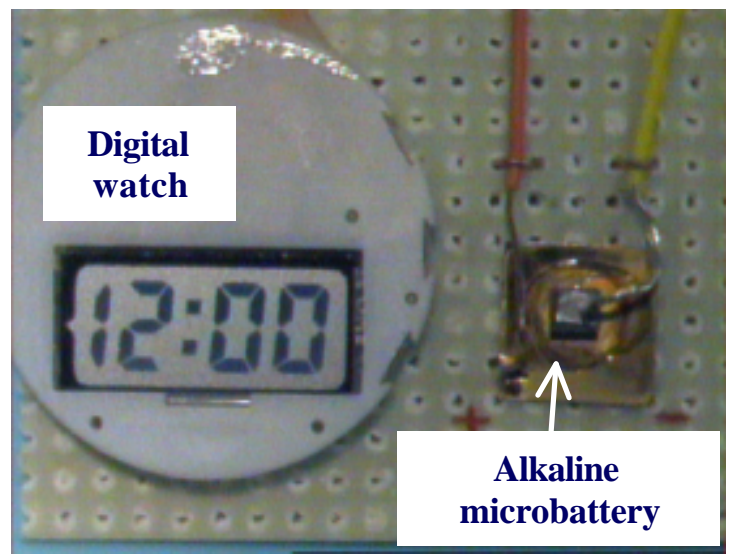

Figure 8. Photograph showing a prototype $\mathrm{Zn} / \mathrm{MnO}_{2}$ alkaline microbattery powering a digital watch.

\subsection{Li-ion Microbatteries}

The laser transferred lithium-ion electrodes show favorable charge and discharge characteristics on early cycles as shown on Figure 9. Figure 9(a) depicts the $4^{\text {th }}$ cycle of charging a lithium cobalt oxide cathode and superimposed on the same figure is its discharge behavior. The electrode was successfully cycled between $4.18 \mathrm{~V}$ and $3 \mathrm{~V}$ and 
exhibited near theoretical capacity. ${ }^{17)}$ The $6^{\text {th }}$ cycle of the carbon anode charge (to $50 \mathrm{mV}$ ) and discharge (to $1 \mathrm{~V}$ ) is shown in Figure 9(b). Although the efficiency of the carbon anode is not as high as that of the lithium cobalt oxide cathode, it shows satisfactory performance at early cycles before break-in is complete. It is important to note that near theoretical charging capacities were obtained. A prototype Li-ion microbattery was assembled in a dry environment by placing a lithium gel electrolyte between the electrodes and then pressing them together. The resulting structure was then attached to a circuit for testing and evaluation. Figure 10 shows a photograph of a prototype Li-ion microbattery connected to a blinking LED circuit. At the time of writing this paper, this Li-ion
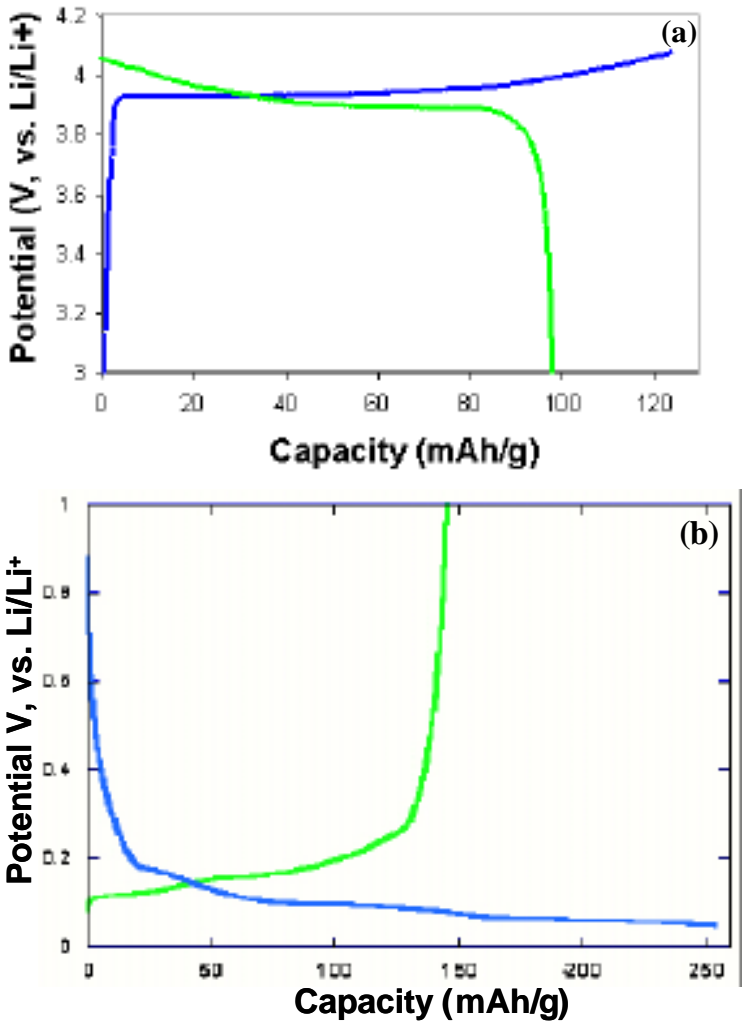

Figure 9(a) $C / 12$ charge and discharge behavior on the $4^{\text {th }}$ cycle of a laser transferred $\mathrm{LiCoO}_{2}$ cathode in $1 \mathrm{M} \mathrm{LiClO}_{4}$ between 3.0 and $4.18 \mathrm{~V}$ vs. $\mathrm{Li} / \mathrm{Li}^{+}$. Figure 9(b) $\mathrm{C} / 12$ charge and discharge behavior on the $6^{\text {th }}$ cycle of a laser transferred $\mathrm{LiCoO}_{2}$ cathode in $1 \mathrm{M} \mathrm{LiClO}_{4}$ between 1.0 and $0.05 \mathrm{~V}$ vs. $\mathrm{Li} / \mathrm{Li}^{+}$.

microbattery had not been tested.

\section{Summary}

MAPLE DW is an ideal process for the direct-write of sensors and microbatteries since it operates in air and at low temperatures. It is compatible with many types of substrates and conditions which are ideal for the processing of the numerous and dissimilar materials required for the fabrication of physical and chemical sensors as well as microbatteries. MAPLE DW has been used for rapid prototyping of custom-engineered sensors and microbatteries in various types of geometries. The versatility and CAD/CAM features of the MAPLE DW technique allow sensor elements and complete sensor systems to be easily reconfigured and integrated with other components. This same approach is also useful for the fabrication of microbatteries in various configurations in order to meet the desired power requirements of a microelectronic system. The microbatteries so far

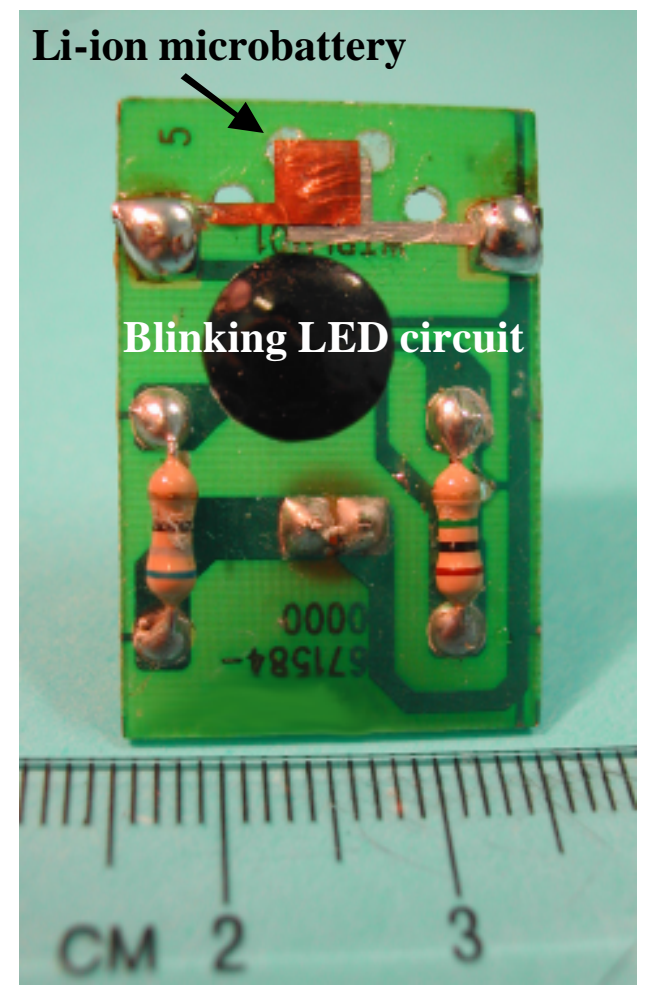

Figure 10. Photograph of a Prototype Li-ion microbattery connected to a blinking LED circuit.

demonstrated by MAPLE DW are not yet optimized and extensive work in developing appropriate current collectors and packaging schemes is still needed before any of these devices can be integrated into microelectronic circuits. However, the potential for the MAPLE DW technique to play a significant role in the development of the next generation of micropower sources is clear.

The authors would like to thank S. A. Mathews and M. T. Duignan for their help in the fabrication of the self contained chemical sensor and T.E. Sutto for providing he lithium gel electrolyte. This work was supported by the Office of Naval Research and DARPA, through the DARPA-MICE program. 


\section{References}

1) A. Piqué and D.B. Chrisey, editors, Direct-Write Technologies for Rapid Prototyping Applications, Academic, San Diego CA, 2001.

2) D.J. Hayes and D.B. Wallace, SPIE Proceedings, 2920, 296, (1996).

3) D. Dimos and P. Yang, Proc. of 48th Electronic Components and Technology Conf., Seattle, Washington, p. 225 (IEEE, New York, 1998).

4) C.P. Christensen, M.T. Duignan and L.R. Rodriguez, SPIE Proceedings, 1835, 128, (1993).

5) D.J. Ehrlich and J.Y. Tsao, editors. Laser Microfabrication: Thin Film Processes and Lithography, Academic, Boston, 1989.

6) A. Piqué, D.B. Chrisey, R.C.Y. Auyeung, S. Lakeou, R. Chung, R.A. McGill, P.K. Wu, M. Duignan, J. FitzGerald, and H. D. Wu, SPIE Proceedings, 3618, 330, (1999).

7) A. Piqué, D.B. Chrisey, R.C.Y. Auyeung, J. FitzGerald, H.D. Wu, R.A. McGill, S. Lakeou, P.K. Wu, V. Nguyen and M. Duignan, Appl. Phys. A, 69, S279 (1999).

8) D.B. Chrisey, A. Piqué, J.M. Fitz-Gerald, R.C.Y. Auyeung, R.A. McGill, H.D. Wu and M. Duignan, Appl. Surf. Sci., 154, 593 (2000).

9) A. Piqué, D.B. Chrisey, J.M. Fitz-Gerald, R.A. McGill, R.C.Y. Auyeung, H.D. Wu, S. Lakeou, V.
Nguyen, R. Chung and M. Duignan, J. Mater. Res., 15, 1872 (2000).

10) J.M. Fitz-Gerald, A. Piqué, D.B. Chrisey, P.D. Rack, M. Zeleznik, R.C.Y. Auyeung and S. Lakeou, Appl. Phys. Lett., 76, 1386 (2000).

11) K.E. Swider-Lyons, D.W. Weir, C.T. Love, R. Modi, T. Sutto, A. Piqué and D.B. Chrisey, Power Sources for the Next Millenium, edited by M. Jain, M.A. Ryan, S. Surampdi, R.A. Marsh and G. Nagrajan, Electrochem. Soc. Proc., 2000-22, 272 (2000).

12) A. Piqué, K.E. Swider-Lyons, D.W. Weir, C.T. Love, R. Modi, SPIE Proceedings, 4274, 317, (2001).

13) P.K. Wu, B. Ringeisen, J. Callahan, M. Brooks, D.M. Bubb, H.D. Wu, A. Piqué, B. Spargo, R. A. McGill and D.B. Chrisey, Thin Solid Films, 398-399, 607 (2001).

14) B. Ringeisen, D.B. Chrisey, A. Piqué, H.D. Young, R. Modi, M. Bucaro, J. Jones-Meehan and B.J. Spargo, Biomaterials, 23, 161 (2002).

15) J.W. Gardner, M. Craven, C. Dow, E.L. Hines, Meas. Sci. Technol., 9, 120 (1998).

16) J.V. Hatfield, P. Neaves, P.J. Hicks, K. Persaud, P. Travers, Sens. Actuators B: Chem., 18, 221 (1994).

17) D. Linden and T.B. Reddy, editors, Handbook of Batteries, Third Edition, McGraw-Hill, New York NY, 2002. 